\title{
Microplane Model for Concrete: II: Data Delocalization AND VERIFICATION
}

\author{
By Zdeněk P. Bažant, ${ }^{1}$ Fellow, ASCE, Yuyin Xiang, ${ }^{2}$ Mark D. Adley, ${ }^{3}$ Pere C. Prat, ${ }^{4}$ and \\ Stephen A. Akers ${ }^{5}$
}

\begin{abstract}
The new microplane model developed in the preceding companion paper is calibrated and verified by comparison with test data. A new approximate method is proposed for data delocalization, i.e., decontamination of laboratory test data afflicted by localization of strain-softening damage and size effect. This method, applicable more generally to any type of constitutive model, is based on the series-coupling model and on the size-effect law proposed by Bažant. An effective and simplified method of material parameter identification, exploiting affinity transformations of stress-strain curves, is also given. Only five parameters need to be adjusted if a complete set of uniaxial, biaxial, and triaxial test data is available, and two of them can be determined separately in advance from the volumetric compression curve. If the data are limited, fewer parameters need to be adjusted. The parameters are formulated in such a manner that two of them represent scaling by affinity transformation. Normally only these two parameters need to be adjusted, which can be done by simple closedform formulas. The new model allows good fit of all the basic types of uniaxial, biaxial, and triaxial test data for concrete.
\end{abstract}

\section{INTRODUCTION}

Following the general theoretical formulation in the preceding paper (Bažant et al. 1996), we will calibrate and verify the new microplane model by fitting the most relevant test data from the literature. To do that properly, we will attempt to decontaminate the data afflicted by localization of damage within the gauge length.

\section{DELOCALIZATION OF TEST DATA AND MATERIAL IDENTIFICATION}

So far it has been general practice to identify the postpeak stress-strain relation from test data ignoring the fact that the deformation of the specimen within the gauge length often becomes nonuniform, due to localization of cracking damage. The fact that damage must localize, except in the smallest possible specimens, had become theoretically clear during the mid-1970s [Bažant (1976); also see the review in Bažant and Cedolin (1991)]. The localization was systematically documented for uniaxial compression by van Mier $(1984,1986)$ and for uniaxial tension by Petersson (1981). However, because the general problem of identification of material parameters in presence of strain-softening localization (Ortiz 1987) is tremendously complex, the contamination of test data by localization has typically been ignored. At the present state of knowledge, however, this is no longer acceptable. The data must be decontaminated and delocalized. An approximate procedure to do that, applicable to any type of constitutive model, was briefly outlined at a recent conference (Bažant et al. 1994) and will now be developed in detail.

\footnotetext{
${ }^{1}$ Walter P. Murphy Prof. of Civ. Engrg. and Mat. Sci., Northwestern Univ., Evanston, IL 60208.

${ }^{2}$ Grad. Res. Asst., Northwestern Univ., Evanston, IL.

${ }^{3}$ Res. Civ. Engr., U.S. Army Engr. Wtrwy. Experiment Station (WES), Vicksburg, Miss.

"Visiting Scholar at Northwestern Univ.; Assoc. Prof. on leave from Polytechnic Univ. of Catalunya, Barcelona, Spain.

'Res. Civ. Engr., U.S. Army Engr. Wtrwy. Experiment Station (WES), Vicksburg, Miss.

Note. Associate Editor: Robert Y. Liang. Discussion open until August 1, 1996. Separate discussions should be submitted for the individual papers in this symposium. To extend the closing date one month, a written request must be filed with the ASCE Manager of Journals. The manuscript for this paper was submitted for review and possible publication on September 19, 1994. This paper is part of the Journal of Engineering Mechanics, Vol. 122, No. 3, March, 1996. OASCE, ISSN 0733-9399/96/ $0003-0255-0262 / \$ 4.00+\$ .50$ per page. Paper No. 9253
}

The delocalization cannot, and need not, be done with a high degree of accuracy and sophistication. In the identification of the present model, the test data from laboratory specimens have been analyzed taking into account the strain localization in an approximate manner, briefly outlined in a recent conference paper (Bažant et al. 1994). The idea is to exploit two simple approximate concepts: (1) localization in the series-coupling model (Bažant 1976); and (2) the effect that energy release due to localization within the cross section of specimen has on the maximum load, as described by the size-effect law proposed by Bažant (1984).

The strain as commonly observed is the average strain $\bar{\varepsilon}$ on a gauge length $L$. According to the series coupling model (BaŽant and Cedolin 1991, section 13.2), $L \bar{\varepsilon}=l \varepsilon_{c}+(L-l) \varepsilon_{u}$, in which $L=$ gauge length on which the deformation is measured; $l=$ length (or width) of the strain-softening zone (measured in the same direction as $L$; Fig. 1(a); $\varepsilon_{c}=$ actual strain in the strain-softening cracking zone [Fig. 1(b)] that needs to be determined; and $\varepsilon_{u}=$ strain in the rest of the specimen, which undergoes unloading from the peak stress point [Fig. 1(b)]. Although in Fig. 1(a) the zone of strain-softening localization is pictured at the left end, the formula is the same if this zone lies anywhere within the gauge length $L$. The unloading strain is $\varepsilon_{u}=\varepsilon_{p}-\left(\sigma_{p}-\sigma\right) / E$, where $E=$ Young's modulus; and $\varepsilon_{p}$ and $\sigma_{p}=$ strain and stress at the peak of the stress-strain curve for the given type of loading. So
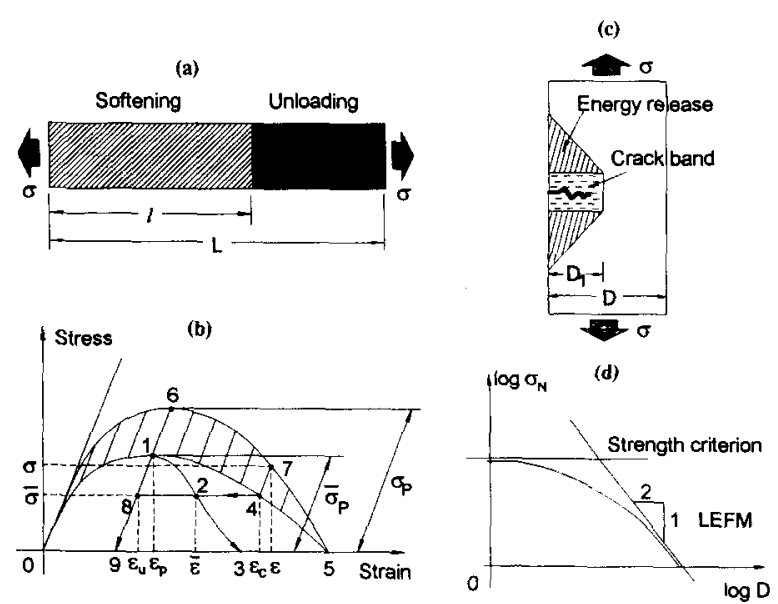

FIG. 1. Filtering of Straln-Softening Localization and SIze Effect from Laboratory Test Data

JOURNAL OF ENGINEERING MECHANICS / MARCH $1996 / 255$ 


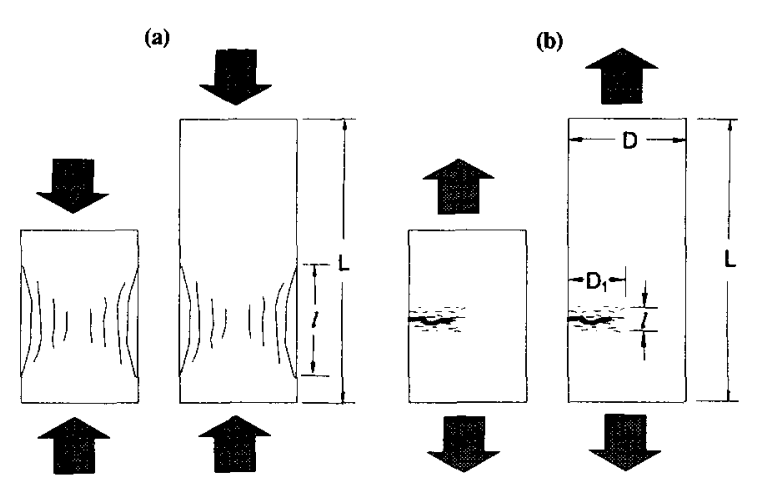

FIG. 2. Typical Patterns of Cracking Localization in Postpeak Response of Compression and Tenslle Specimens: (a) Compression; (b) Tension

$$
\text { for } \bar{\varepsilon}>\varepsilon_{p}: \quad \varepsilon_{c}=\frac{L}{l} \bar{\varepsilon}-\frac{L-l}{l}\left(\varepsilon_{p}-\frac{\sigma_{p}-\bar{\sigma}}{E}\right)
$$

The strain that the constitutive model for damage should predict is the strain $\varepsilon$ in the localization zone. But this strain is difficult to measure, for three reasons: The size of the localization zone is small, which reduces the accuracy of strain measurements; the location of the localization zone is uncertain, and so one does not know where to place the gauge; and the deformation of the localization zone is quite random, while the constitutive model predicts the statistical mean of many random realizations (determining this mean requires taking measurements on many specimens).

To correct the given test data according to (1), one must obviously know the value of the localization length $l$. It is impossible to determine this length from the reports on the uniaxial, biaxial, and triaxial tests of concrete found in the literature. However, a reasonable estimate can be made by experience from other studies; $l \approx 3 d_{a}$, where $d_{a}=$ maximum size of the aggregate in concrete (for high-strength concretes, $l$ is likely smaller, perhaps as small as $l=d_{a}$ ).

According to the available uniaxial test results, extending only the length of the specimen does not appear to have a systematic effect on the measured peak load or strength; however, changing the cross-section size $D$ does. This type of size effect is not describable by the series coupling model. Rather, the response is a complex mixture of series and parallel couplings of the strain-softening localization zone and the unloading zone. Such behavior is better looked at in a different way - through the energy release.

A localized zone of cracking damage causes energy to be released not only from the damage zone itself but also from the adjacent zone that is getting unloaded. This is graphically illustrated in Fig. 1(c), where the energy is released not only from the damage-localization zone (i.e., the cracking band), but also from the adjacent shaded zones, which may be approximately assumed as triangular. This consideration shows that in a larger specimen that is geometrically similar and contains a geometrically similar crack, the energy-release rate for the same applied average stress is higher. But the energy consumption at the front of the propagating crack band per unit extension of the band is the same, being a material property. Therefore, the applied stress in the larger specimen must be smaller, so that the energy-release rate be equal to the energyconsumption rate. This approximate consideration yields the size-effect law (Bažant 1984): $\bar{\sigma}_{p}=\sigma_{0}\left[1+\left(D / D_{0}\right)\right]^{-1 / 2}$, in which $\sigma_{N}=$ nominal strength of the material $=$ average stress in the cross section at the peak load; $D=$ characteristic dimension, which may be taken as the cross-section dimension; and $D_{0}$ and $\sigma_{0}=$ empirical constants depending on material properties, specimen shape, and type of loading. The term $\sigma_{0}$ theoretically represents the strength for $D \rightarrow 0$, which is a limiting value that is usually approached only for extrapolations to specimen size less than $d_{a}$, which has no physical meaning.

We need to refer the strength values to a certain representative volume of the material that is approximately equal to the size of the localization zone, that is, size $D_{1} \sim l$ [Fig. 1(d)]. For this representative size we have $\varepsilon=\varepsilon_{c}+(\bar{\sigma}-\sigma) / E$. Thus, the corrected peak stress (strength) may be approximately determined as

$$
\sigma_{p}=\alpha_{p} \bar{\sigma}_{p} ; \quad \alpha_{p}=\sqrt{\frac{1+\left(D / D_{0}\right)}{1+\left(l / D_{0}\right)}}
$$

where $\bar{\sigma}_{p}=$ actually measured average stress in the cross section at the peak load.

The size effect obviously modifies not only the strength, but all the stress values. We may consider that, due to a change of size from $D$ to $D_{1}$, the stress-strain curve is approximately transformed as shown by arrows in Fig. 1(b). This type of transformation, considered as affinity scaling in the direction of arrows with respect to the strain axis, does not change the initial elastic modulus $E$. Thus, all the measured average stresses in the cross section, $\bar{\sigma}$, need to be transformed as $\sigma=$ $\alpha_{p} \tilde{\sigma}$. The corresponding strains change by the horizontal projections of the arrows in Fig. 1(b), and so they are $\varepsilon=\varepsilon_{c}+$ $(\boldsymbol{\sigma}-\overline{\boldsymbol{\sigma}}) / E$. Therefore

$$
\varepsilon=\varepsilon_{c}+\frac{\alpha_{p}-1}{E} \bar{\sigma} ; \quad \sigma=\alpha_{p} \bar{\sigma}
$$

in which $\varepsilon$ and $\sigma=$ corrected strains and stresses for the representative volume of the material to be described by the microplane model. The value of $\varepsilon_{c}$ is calculated from (1). The actually measured average stresses and strains, as reported in the literature, are $\bar{\sigma}$ and $\bar{\varepsilon}$.

The transformations of measured data are explained in Fig. 1(b). The average stresses and strains as measured yield the stress-strain diagram 0123. According to the series coupling model, this diagram needs to be transformed to 0145. According to the energy-release effect described by size-effect law, this diagram needs to be further transformed to 0675. This then represents the correct stress-strain diagram to be represented by the constitutive model. A general point 2 on the softening diagram, having coordinates $\varepsilon$ and $\bar{\sigma}$, is first transformed according to the series coupling model to point 4 having coordinates $\varepsilon_{c}$ and $\bar{\sigma}$, and this point is then transformed according to the size-effect law to point 7 , having coordinates $\varepsilon$ and $\sigma$ to be used in the constitutive model. The geometrical meaning of the affinity transformation according to the horizontal arrows is that $\overline{84} / \overline{82}=L / l$, and the geometrical meaning of the second affinity transformation according to the inclined arrows is that $\overline{96} / \overline{91}=\overline{37} \overline{34}=\alpha_{p}$.

Further questions need to be discussed with respect to the lateral strains and to triaxial deformations. Fig. 2 shows schematically the actual postpeak damage in uniaxially compressed and uniaxially tensioned specimens. For tension, the length (or width) of the localization zone (width) in normal concretes is approximately $l=3 d_{a}$, where $d_{a}=$ maximum aggregate size. For high-strength concrete it is narrower, perhaps $l=d_{\mathfrak{a}}$. In compression, the length of the localization zone, consisting of bands of axial splitting cracks and shear bands, is larger and probably may be taken as $l=D$, where $D=$ width of the cross section. As for the measurements of lateral strains in these tests, it is assumed they are made in the localization zone, and in that case no corrections to those strains are needed (if lateral strains were measured outside the localization zone, then such measurements would be irrelevant to postpeak behavior). Because the volumetric strains are determined from the lateral strains, no correction is applied to these as well. When non- 

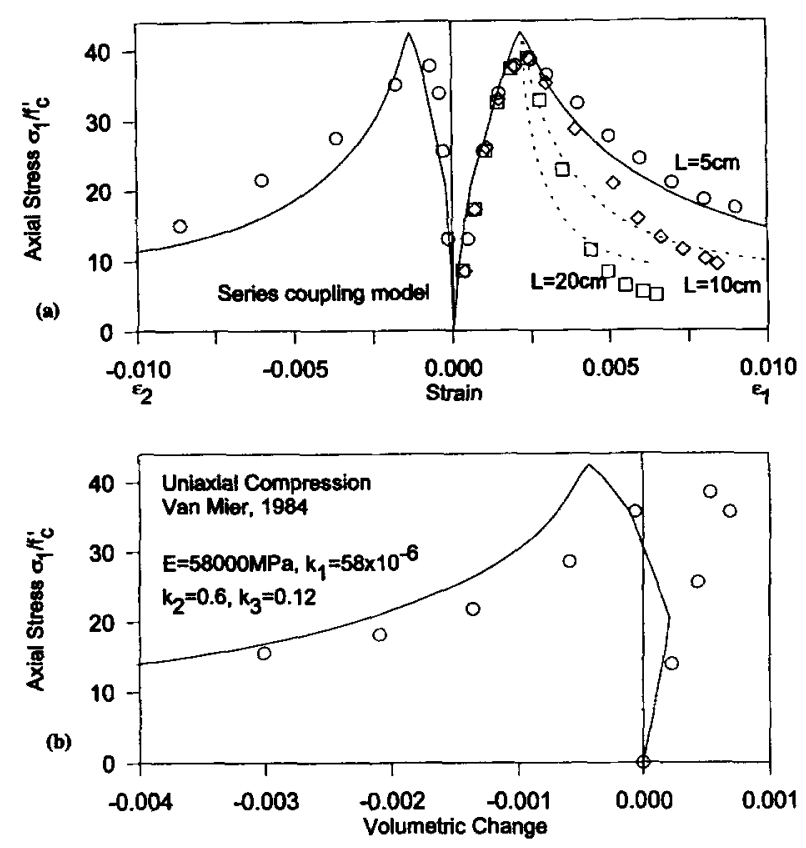

FIG. 3. Fitting of Uniaxlal Compression Test Data by van Mier (1984, 1986)

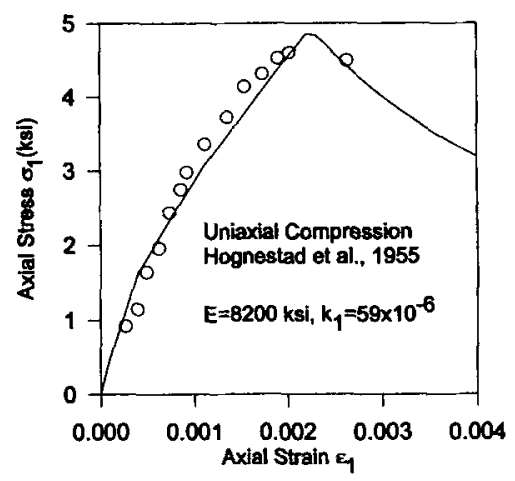

FIG. 4. Fitting of Uniaxial Compression Test Data by Hogenstad (1955)

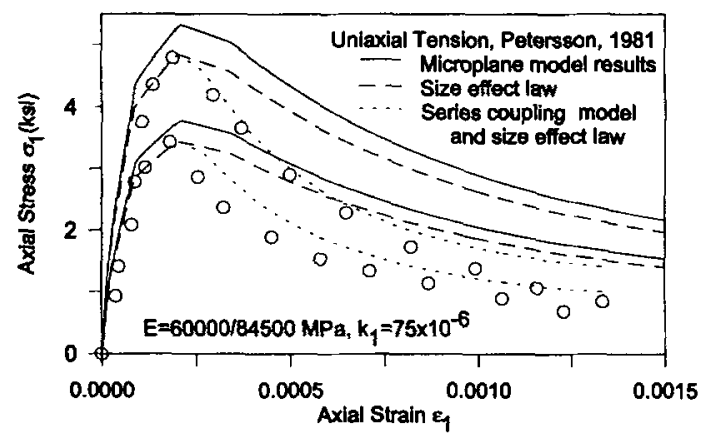

FiG. 5. Fitting of Direct Tenslon Test Data by Petersson (1981)

similar specimens of different lengths and the same cross section are used in uniaxial tests [e.g., van Mier $(1984,1986)]$, the size effect on the maximum stress is approximately zero, as indicated by these tests, and so the correction according to the size-effect law is not applied. This correction should be based on the dimension of the cross section, not on the length of the specimen when dissimilar specimens are considered. In shear tests carried out as torsion tests, the localization is onedimensional, similar to uniaxial tension, and thus the shear strain and shear stress are treated in the same way, with the same corrections.

\section{CALIBRATION AND COMPARISON WITH CLASSICAL TEST DATA}

The present model has been calibrated and compared to the typical test data available in the literature. They included (1) Uniaxial compression tests by van Mier (1984, 1986; Fig. 3), for different specimen lengths and with lateral strains and volume changes measured, and by Hognestad (1955; Fig. 4); (2) uniaxial direct tension tests by Petersson (1981; Fig. 5); (3) uniaxial strain compression tests of Bažant et al. [1986; Fig. 6(a)]; (4) hydrostatic compression tests by Green and Swanson [1973; Fig. 6(b)]; (5) standard triaxial compression tests (hydrostatic loading followed by increase of one principal stress) by Balmer (1949; Fig. 7); (6) tests of shear-compression failure envelopes under torsion by Bresler and Pister (1958) and Goode and Helmy [1967; Fig. 8(a)]; (7) tests of biaxial failure envelope by Kupfer et al. [1969; Fig. 8(b)]; (8) failure envelopes from triaxial tests in octahedral plane ( $\pi$-projection) by Launay and Gachon (1971; Fig. 9); and (9) uniaxial cyclic compression tests of Sinha et al. (1964; Fig. 10).

As seen from the figures, the comparisons are quite good. In Fig. 3 it should be noted that the uniaxial compression stress-strain diagrams are well represented for three specimens lengths, $l=5,10$, and $20 \mathrm{~cm}$ [it was already shown that the series coupling describes well the length effect in these tests; see Bažant and Cedolin (1991), section 13.2]. Fig. 6(a) serves as the basis for calibrating the volumetric stress-strain boundary, and a good fit is seen to be achieved for these enormous compressive stresses (up to $300 \mathrm{ksi}$ or $2,070 \mathrm{MPa}$ ). Fig. 8(b) shows that the ratio of uniaxial and biaxial compression strengths found in these tests can be modeled. Fig. 7 shows
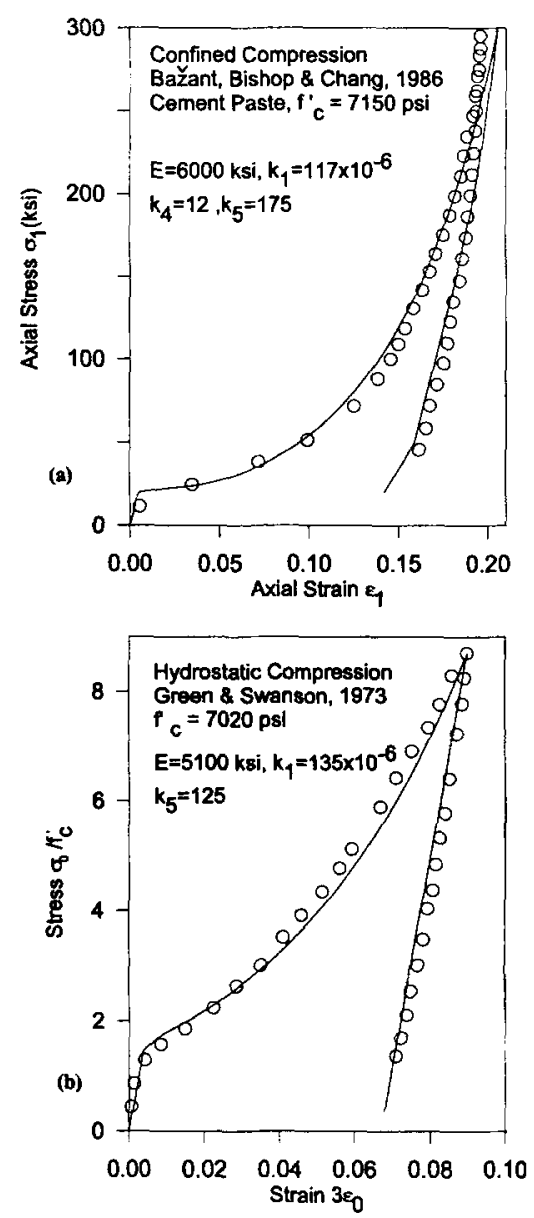

FIG. 6. Fitting of (a) Confined Compression Test (Unlaxial Strain) of Bazant et al. (1986); (b) Hydrostatic Compresslon Test Data by Green and Swanson (1973)

JOURNAL OF ENGINEERING MECHANICS / MARCH 1996 / 257 


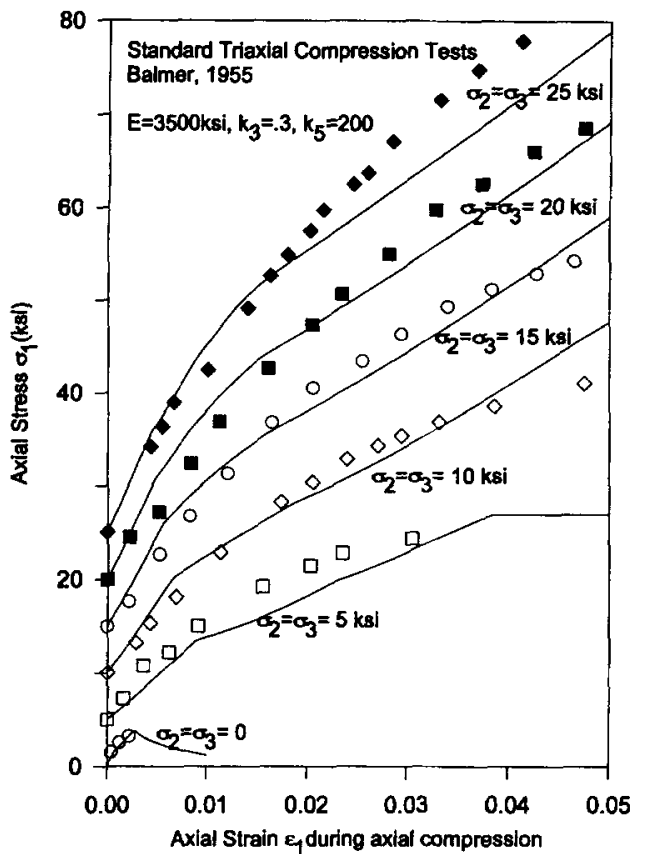

FIG. 7. Fitting of Trlaxial Tost Data (Increasing Axlal Comprossion at Constant Lateral Confining Pressure) by Balmor (1949)
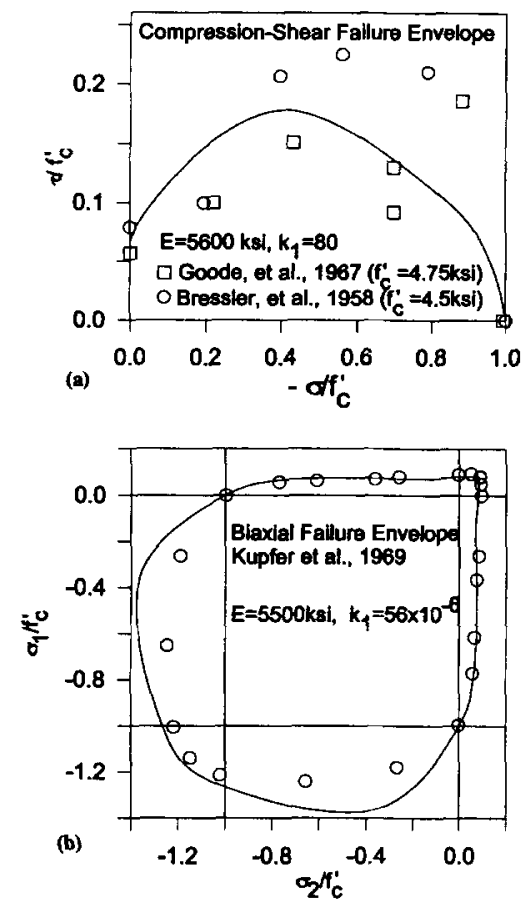

FIG. 8. Fitting of (a) Shear Compression Fallure Envelope (in Toraion) Measured by Bresler (1958); (b) Biaxial Fallure Envelope Measured by Kupfer et al. (1969)

that the large effect of the confining pressure in standard triaxial tests can also be captured. In Fig. 9, note that the model predicts well the shape of the failure envelopes, which is noncircular and nonhexagonal, corresponding to rounded irregular hexagons squashed from three sides. In Fig. 10, note that the subsequent stress peaks in cycles reaching into the softening range are modeled quite correctly, as are the initial unloading slopes. Significant differences, however, appear at the bottom of the cyclic loops, which is due to the fact that the unloading modulus is in the present model kept constant (a refinement would be possible, by changing the constant unloading slope on the microplane level to a gradually decreasing slope, of course with some loss of simplicity). It should also be noted that the loading in these tests was quite slow and much of the curvature may have been due to relaxation caused by creep.

It must be emphasized that all the solid curves plotted in the figures are the curves that are predicted by the microplane model. The dotted curves in Fig. 3 are those after correction according to the series-coupling model. The dashed curves in Fig. 5 are those after correction according to the size-effect law, and the dotted curves are those after a further correction according to the series-coupling model.

The vertex effect is given in Fig. 11.

\section{PREDICTIONS FOR DIFFERENT TYPES OF TESTS OF SAME CONCRETE}

The test results to which the model has so far been compared have been obtained on different concretes, which means

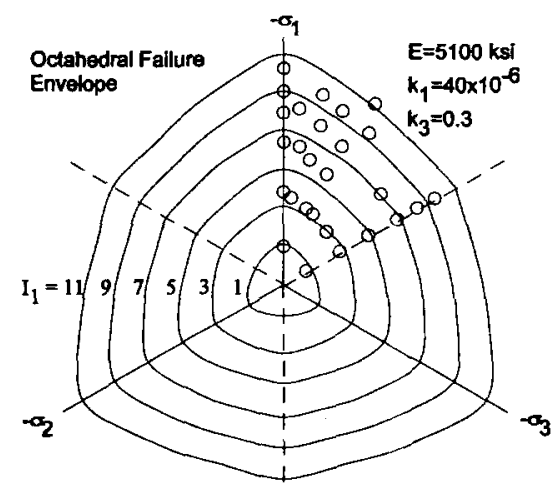

FIG. 9. Fitting of Fallure Envelopes In Hydrostatic Planes at Varlous Pressures Measured by Launay and Gachon (1971)

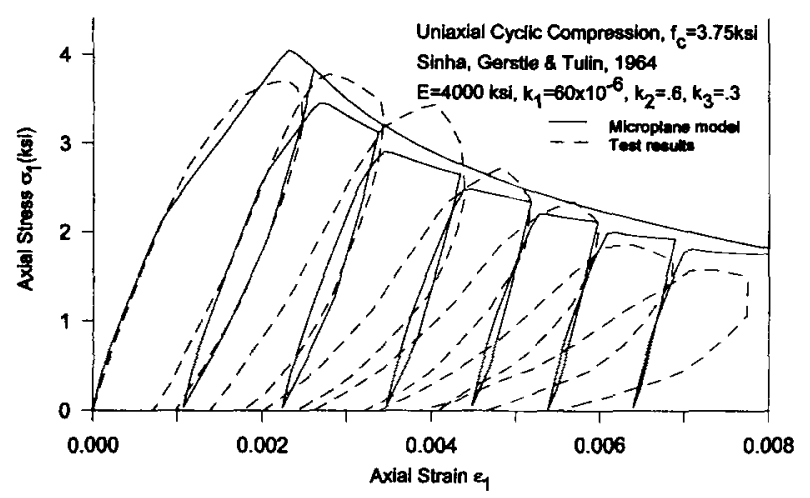

FIG. 10. Fitting of Unlaxial Cyclic Compression Tests of Sinha ot al. (1964)

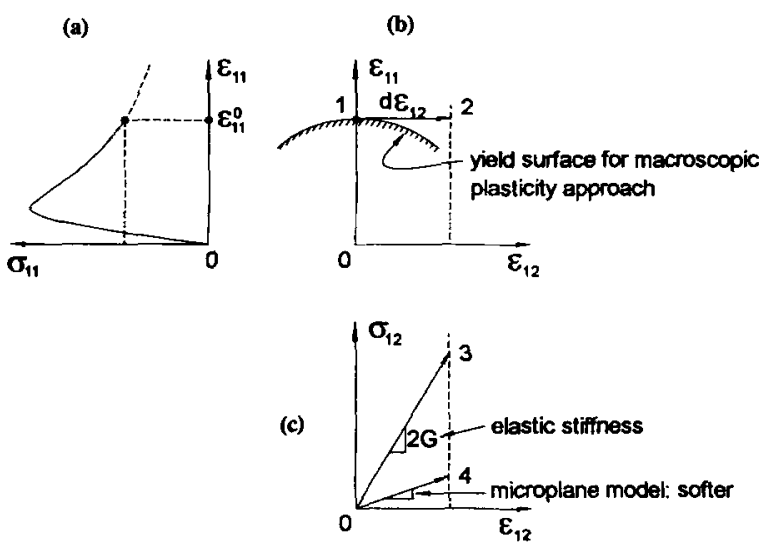

FIG. 11. Vertex Effect 

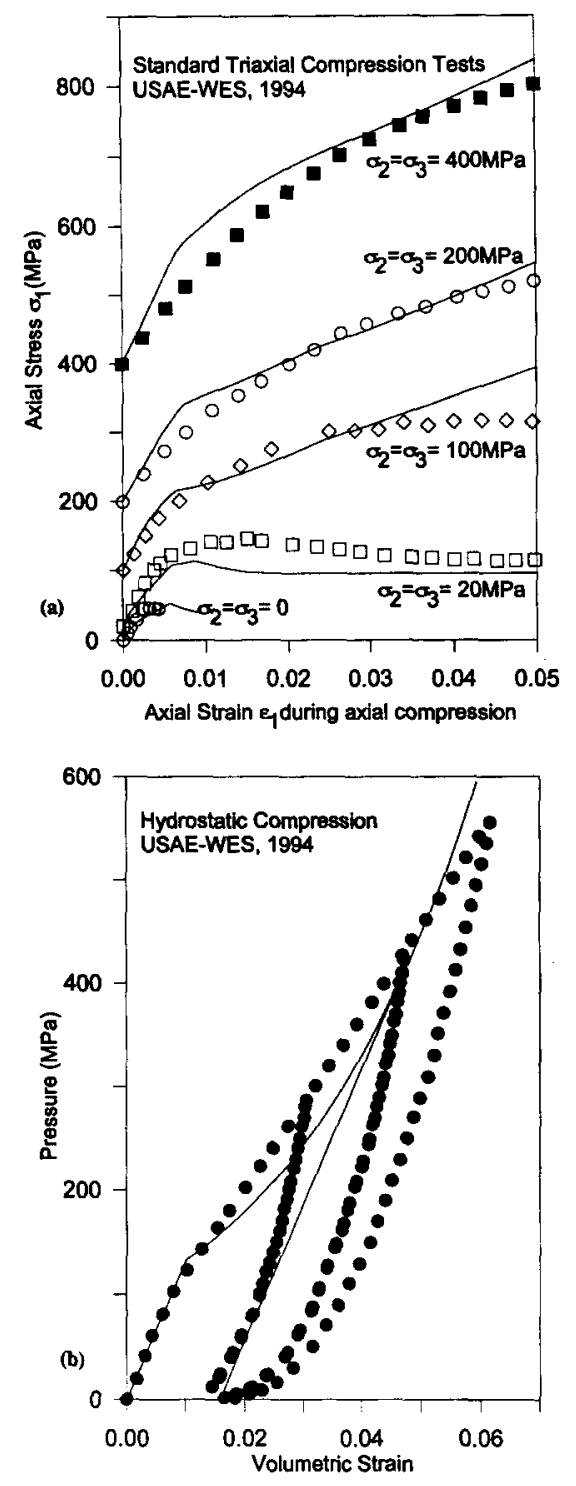

FIG. 12. Callbration of Microplane Model by Optimum Fitting of (a) Standard Trlaxial Data; (b) Hydrostatic Compression Data (Data Points Obtained at WES)

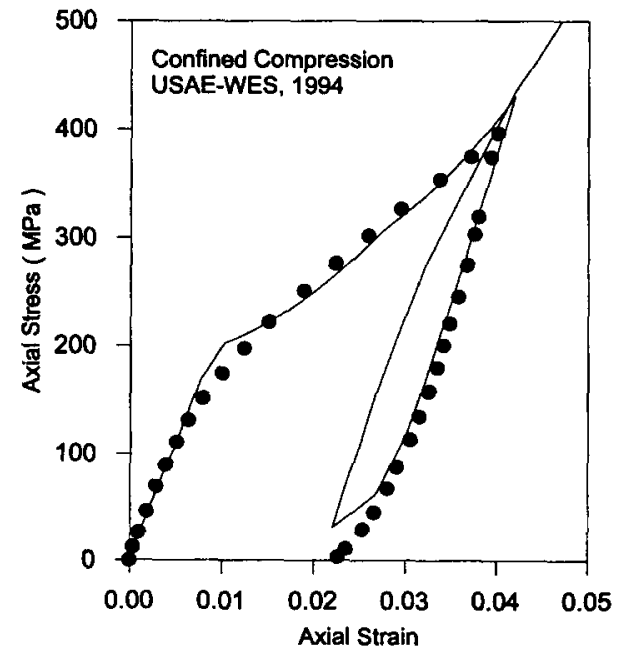

FIG. 13. Curves Predlcted by Mlcroplane Model for Confined Compression Uniaxlal-Strain Tests Compared to Data Points Obtained at WES that different material parameters can be used. A more severe check is a comparison with a set of many different types of tests of the same concrete. To obtain such a set, various special triaxial compression tests under nonproportional stress-strain paths have been conducted at the U.S. Army Engineers Waterways Experiment Station (WES); see Figs. 12-15. Although the strains were not so large that the finite strain theory would be required, they were large enough to make the difference between the Cauchy (or true) stresses $S_{j}$ and the nominal stresses $T_{i j}$ appreciable. The stresses plotted in the figures are $T_{i j}$ (which are also called the engineering stresses, and are for these tests approximately equal to the first Piola-Kirchhoff stresses). The tests have been made on right circular cylinders of initial height $h_{0}=10.16 \mathrm{~cm}$ and initial radius $r_{0}=2.54 \mathrm{~cm}$. The strain field in the cylinders can be assumed to remain uniform. Let $T_{1}$ and $T_{2}=$ axial and lateral (or radial) nominal normal stresses (representing the principal stresses); $e_{1}=(h-$ $\left.h_{0}\right) / h_{0}, e_{2}=e_{3}=\left(r-r_{0}\right) / r_{0}=$ axial and lateral engineering strains (or Biot finite strains); $h$ and $r=$ height and radius of the deformed cylinder; and $e_{1}=u_{1,1}$ and $e_{2}=u_{2,2}$, where $u_{1}$ and $u_{2}=$ axial and lateral displacements. Obviously, $T_{1}=S_{1}$ $\left(1+e_{2}\right)^{2}$ and $T_{2}=S_{2}\left(1+e_{1}\right)\left(1+e_{2}\right)$. The test results are plotted in terms of the nominal principal stress difference and the nominal mean stress (-pressure $p$ ), expressed as

$$
\begin{gathered}
T_{1}-T_{2}=S_{1}\left(1+e_{2}\right)^{2}-S_{2}\left(1+e_{1}\right)\left(1+e_{2}\right) \\
-p=(1 / 3)\left(T_{1}+2 T_{2}\right)=(1 / 3)\left[S_{1}\left(1+e_{2}\right)^{2}+2 S_{2}\left(1+e_{1}\right)\left(1+e_{2}\right)\right]
\end{gathered}
$$
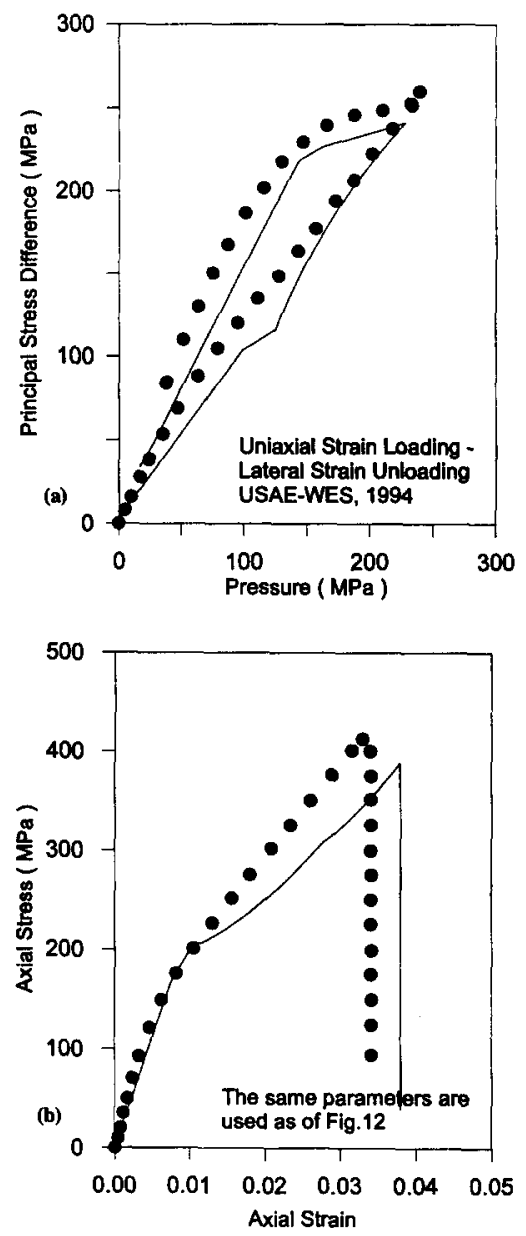

FIG. 14. Predicted Curves for Unlaxial Strain Loading Followed by Lateral Strain Unloading Compared to Data Points Obtained at WES 

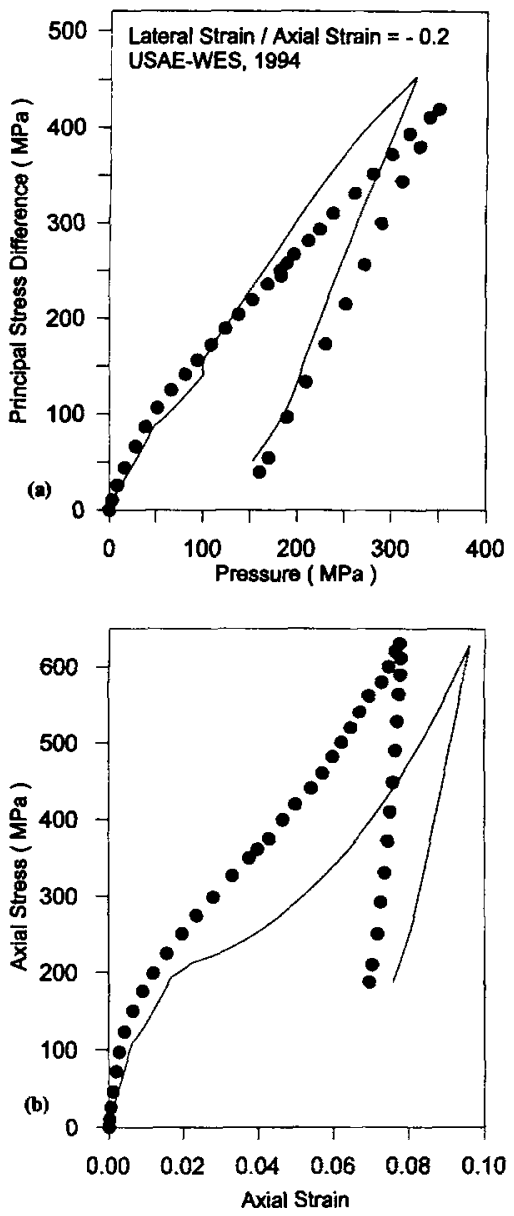

FiG. 15. Predicted Curves for Loading at Constant Ratio of Lateral Straln to Axlal Strain, Equal to -0.2, and Comparison to Data Points Obtained at WES

The data evaluation program provides $S_{i j}$, but here we prefer to plot $T_{i j}$.

The data from these tests were delocalized as described in (1)-(3). The triaxial compression test with confining pressure $20 \mathrm{MPa}$ was delocalized using the values $D_{0}=l=D=5.08$ $\mathrm{cm}, L=10.16 \mathrm{~cm}, \sigma_{p}=146 \mathrm{MPa}$, and $\varepsilon_{p}=1.45 \%$. Since $D_{0}$ $=l=D$, in effect, only the series-coupling model was considered for delocalization while the correction due to the size effect was assumed to be negligible. The softening portion of the unconfined compression test was discarded because its accuracy was suspect, and thus it was not necessary to delocalize that test.

The concrete used in these tests had standard cylindrical compression strength $f_{c}^{\prime}=46 \mathrm{MPa}(6,700 \mathrm{psi})$, unit weight $2,349 \mathrm{~kg} / \mathrm{m}^{3}\left(146.5 \mathrm{lb} / \mathrm{ft}^{3}\right)$, and contained $264.2 \mathrm{~kg} / \mathrm{m}^{3}$ (445 lb/ $\mathrm{yd}^{3}$ ) of Type $\mathrm{I}$ portland cement. The mix ratio (by weight) was cement : fly ash : coarse aggregate (river run gravel-chert, maximum size $9.5 \mathrm{~mm}$ or $3 / 8 \mathrm{in}$.) : fine aggregate (river run sand, maximum size $6.35 \mathrm{~mm}$ or $0.25 \mathrm{in}$.) : water $=1: 0.211$ : $3.930: 3.184: 0.553$; also $2,940 \mathrm{~cm}^{3}$ of water-reducing admixture per cubic meter ( 76 fiuid oz. per cubic yard) were used. The concrete was cured for 28 days prior to testing (cured wet for the first 7 days). The microplane model parameters for this concrete, calibrated by optimal fitting of the standard triaxial test data in Fig. 12, are: $E=25,000 \mathrm{MPa}, k_{1}=150 \times 10^{-6}$, $k_{2}=0.6, k_{3}=0.18, k_{4}=26$, and $k_{5}=73$, while all the remaining parameters are the same as indicated before. Better fits of these and further data from WES could be obtained if parameter $c_{5}$ was changed from 6 to about 1 .

Based on the aforementioned parameter values, predictions are calculated for the nonstandard triaxial tests in Figs. 13-
15. The confining stress (pressure) that was kept constant during the triaxial tests and is indicated in the figure was the Cauchy (true) stress (and not the nominal stress). Fig. 12(a) shows calibration of the microplane models by fitting the triaxial compression test data for several different confining pressures that have been achieved with the present microplane model. As seen, the agreement is close over a wide range of confining pressures. Fig. 12(b) shows further calibration by fitting the hydrostatic compression data. The agreement achieved is excellent for the loading portion of the stress-strain curve; however, the unloading and reloading behaviors of the concrete are not modeled accurately. The reason is that the present version of microplane model assumes the initial modulus for unloading and reloading to be equal to the initial bulk modulus, whereas in reality it strongly depends on the volumetric strain.

Fig. 13 presents a comparison of the model prediction with the results of a uniaxial-strain confined compression test. The agreement is good, although no effort to fit the data optimally has been made. Figs. 14-15 show comparisons of the model predictions with tests for three complex strain paths. The path in Fig. 14 consists of a uniaxial-strain loading followed by a constant axial-strain unloading. The unloading leads to a decrease of pressure, which causes the state point to contact the failure surface and then ride down on it, thereby defining it. Fig. 14(a) reveals that the failure surface predicted by the microplane model is similar, both qualitatively and quantitatively, to the actual failure surface. As seen in Fig. 14(b), the agreement between the predicted and measured axial stress-strain curves for that test is also quite good.

Fig. 15 gives the results for a path with a constant strain ratio $e_{1} / e_{2}=-0.2$, for both loading and unloading. As one can see, this path causes the current state point to ride up along the failure surface during loading. Fig. 15(a) reveals that the failure surface predicted by the microplane model closely agrees with the surface observed in the laboratory. As shown in Fig. 15(b), the axial stress-strain curve is qualitatively correct although the magnitudes of the predicted stresses are a little bit low.

Given that the curves in Figs. 13-15 are not optimized fits but predictions, the comparisons are quite satisfactory. They confirm the predictive capability of the model.

\section{VERTEX EFFECTS}

There is another important property that is exhibited by the microplane model, and not, for example, by macroscopic plasticity models. For a nonproportional path with an abrupt change of direction such that the load increment in the $\sigma_{i}$ space is directed parallel to the current yield surface, the response of a plasticity model is perfectly elastic, unless this change of direction happens at a corner of the yield surface. But in reality, for all materials, this response is softer, in fact much softer, than elastic. It is as if a corner or vertex of the yield surface traveled with the state point along the path.

This effect, called the vertex effect [see, e.g., section 10.7 in Bažant and Cedolin (1991)], is automatically described by the microplane model, but is next to impossible to model with the usual plastic or plastic-fracturing models. It can be described only by models with many simultaneous yield surfaces, which are prohibitively difficult in the $\sigma_{y}$ space. The microplane model is in effect equivalent to a set of many simultaneous yield surfaces, one for each microplane component (although these surfaces are described in the space of microplane stress components rather than in the $\sigma_{i j}$ space). This is one important advantage of the microplane approach. It is, for example, important for obtaining the correct incremental stiffness for the case when a $d \varepsilon_{12}$-increment (segment $\overline{12}$ in Fig. 11 ) is superimposed on a large strain $\varepsilon_{11}^{0}$ (segment 01 ) in the 
inelastic range. Segment $\overline{03}$ in Fig. 11 is the predicted response according to all classical macroscopic models with yield surfaces, which is elastic, and segment $\overline{04}$ is the prediction of microplane model, which is often much softer than elastic (i.e., $d \sigma_{12} / d \varepsilon_{12}<2 G$, where $G=$ elastic shear modulus).

Fig. 11 shows the incremental stiffness $\overline{04}$ calculated for the case for the present reference parameters and $\varepsilon_{11}^{0}=0.005$. Indeed, the slope $\overline{04}$ is almost $1 / 5$ of the slope $\overline{03}$ which would be predicted by plasticity with a simple yield surface.

\section{NONLOCAL GENERALIZATION}

Finally it must be emphasized that strain softening can be modeled only if the microplane model is combined with a nonlocal concept. As recently shown (Bažant 1994a), the nonlocality is a necessary consequence of microcrack interactions and is a property that is separate from the stress-strain relation.

The microplane model, or for that matter any constitutive model for damage, gives a prescription how to calculate the stress tensor $\sigma$ as some tensor-valued function $f$ of the strain tensor $\varepsilon$. So, $\sigma=f(\varepsilon)$. The most robust method of structural analysis is to base the solution of a loading step on the incremental elastic stress-strain relation with inelastic strain involving the initial elastic moduli tensor $\mathbf{E}$

$\Delta \sigma=E: \Delta \varepsilon-\Delta S ; \quad \Delta S=E:\left(\varepsilon_{\text {new }}-\varepsilon_{\text {old }}\right)-\mathbf{f}\left(\varepsilon_{\text {new }}\right)+f\left(\varepsilon_{\text {old }}\right)$

in which subscripts "old" and "new" refer to the values of the variables at the beginning and end of the loading step; and $\mathbf{S}=$ inelastic stress tensor due to nonlinear behavior. In static implicit analysis (iterative initial stiffness method), $\Delta \mathbf{S}$ is updated in each load step by iterations. In the first iteration, $\boldsymbol{\varepsilon}_{\text {new }}$ and $\varepsilon_{\text {old }}$ are estimated on the basis of the solution of the previous load step.

There are various types of nonlocal approach. In the isotropic scalar nonlocal approach (Pijaudier-Cabot and Bažant 1987), which was applied to the previous microplane model by Bažant and Ožbolt $(1990,1992)$ and Ožbolt and Bažant (1994), the elastic parts of stress increments are calculated locally. The inelastic parts of the increments of $\mathbf{S}$ must be calculated nonlocally. This is accomplished by first determining, at each integration point of each finite element, the spatial weighted average (or nonlocal) strains $\langle\boldsymbol{\varepsilon}\rangle$, and then calculating nonlocal $\overline{\mathbf{A S}}$ from these, i.e.

$$
\begin{gathered}
\Delta \boldsymbol{\sigma}=\mathbf{E}: \Delta \varepsilon-\overline{\Delta \mathbf{S}} \\
\overline{\Delta \mathbf{S}}=\mathbf{E}:\left(\left\langle\varepsilon_{\text {old }}\right\rangle-\left\langle\varepsilon_{\text {new }}\right)\right)-\mathbf{f}\left(\left\langle\varepsilon_{\text {new }}\right\rangle\right)+\mathbf{f}\left(\left\langle\varepsilon_{\text {old }}\right\rangle\right)
\end{gathered}
$$

in which \langle\rangle denotes the operation of spatial weighted averaging, approximated by a sum over the integration points of nearby finite elements. The only modification required in a local finite-element program is to insert the spatial averaging subroutine just after $\Delta \mathbf{S}$ is evaluated.

There exists a better, more recent, nonlocal model, which is directly derived from crack interactions (Bažant 1994a) but is more complicated. This model has been combined with the previous microplane model (Ožbolt and Bažant 1994) and could be similarly combined with the present one.

\section{CONCLUSIONS}

1. The response of a quasi-brittle material such as concrete can be characterized on the microplane level as elastic within certain stress-strain boundaries that can never be exceeded. The response must follow the boundary, which describes strain softening. The advantage of this new concept is that each boundary can be defined as a function of different variables (strain components) than the other boundaries and the elastic behavior. This feature is useful and necessary for the description of tensile strain softening.

2. Although separately the elastic behavior and the movement along the boundaries are path independent, the total response is path dependent as a consequence of different possible combinations of elastic loading or unloading and strain softening.

3. The new idea of stress-strain boundaries makes it possible to obtain an excellent representation of nonlinear triaxial behavior of concrete with strain softening. The constitutive model can have an explicit form, in which the stresses are calculated from the strains. The new model is simpler than the previous microplane model. Use of the boundaries also allows an easy description of the response at unloading and cyclic loading.

4. For compressive behavior, the stress-strain boundaries must be formulated separately for volumetric and deviatoric components. For tensile behavior, the boundary must be prescribed in terms of the total normal strain, even though the tensile elastic response is described separately for the deviatoric and volumetric components. This eliminates a problem with excessive lateral strains that developed at very large tensile strains in the previous microplane formulation. For shear, the boundary can be defined simply as a linear frictional yield condition with cohesion.

5. Identification of the material parameters from test data is made easy by introduction of several parameters that effect affinity transformations of the stress-strain curves.

6. A simplified method to delocalize the data, i.e., make correction to eliminate localization of strain softening and size effect due to energy release in the evaluation of laboratory test data, is proposed. The method is made simple by using the series coupling model for localization and the size-effect law. Such an approach to delocalization and material identification yields a stress-strain relation that describes approximately the behavior of a small representative volume of the material rather than the average behavior of the test specimens.

7. Generalization to moderately large finite strain is the easiest if the Lagrangian (or Green's) strain is adopted as the finite strain measure. Instead of considering other choices of finite strain measure, it is easier (and equivalent) to modify the tail of the microplane constitutive relations. The constitutive relations for the microplane are selected so that concrete at large strains, reduced to rubble, behaves approximately as a granular material.

\section{ACKNOWLEDGMENTS}

Partial financial support for both this and the preceding paper for Z.P. Bažant under Contract No. DACA39-94-C-0025 between the U.S. Army Engineer Waterways Experiment Station, Vicksburg, Miss., and Northwestern University is gratefully acknowledged. Additional support has been received from the Center for Advanced Cement Based Materials at Northwestern University. Thanks are due to Milan Jirásek, assistant professor at Czech Technical University (ČVUT), Prague, and visiting postdoctoral research associate at Northwestern University, for his valuable critical studies, comments, and discussions, which revealed certain problems with a preliminary version of the present model.

\section{APPENDIX. REFERENCES}

Balmer, G. G. (1949). "Shearing strength of concrete under high triaxial stress-computation of Mohr's envelope as a curve." Rep. No. SP. 23, Struct. Res. Lab., Denver, Colo.

Bažant, Z. P. (1976). "Instability, ductility, and size effect in strain-softening concrete." J. Engrg. Mech. Div., ASCE, 102(2), 331-344 (disc. 103, 357-358, 775-777, 104, 501-502).

Bažant, Z. P. (1984). "Size effect in blunt fracture: Concrete, rock, metal." J. Engrg. Mech., ASCE, 110(4), 518-535. 
Bažant, Z. P. (1994a). "Nonlocal damage theory based on micromechanics of crack interactions." J. Engrg. Mech., ASCE, 120(3), 593-617.

Bažant, Z. P. (1994b). "Finite-strain generalization of small-strain constitutive relations and volumetric-deviatoric split." Rep. 94-12/403f, Dept. of Civ. Engrg., Northwestern Univ., Evanston, Ill.; also Intern. J. of Solids and Structures (in press).

Bazant, Z. P., Bishop, F. C., and Chang, T.-P. (1986). "Confines compression tests of cement paste and concrete up to $300 \mathrm{ksi}$." J. Am. Concrete Inst., 33(4), 553-560.

Bažant, Z. P., and Cedolin, L. (1991). Stability of structures: Elastic, inelastic, fracture and damage theories (textbook and reference volume), Oxford University Press, New York, N.Y.

Bažant, Z. P., Jirásek, M., Xiang, Y., and Prat, P. C. (1994). "Microplane model with stress-strain boundaries and its identification from tests with localized damage." Proc., Computational Modeling of Concrete Struct. (EURO-C), H. Mang, et al., eds., Pineridge Press, Swansea, Wales, 255-261.

Bažant, Z. P., and Ožbolt, J. (1990). "Nonlocal microplane model for fracture, damage and size effect in structures." J. Engrg. Mech., ASCE, $116(11), 2484-25054$

Bažant, Z. P., and Ožbolt, J. (1992). "Compression failure of quasi-brittle material: Nonlocal microplane model." J. Engrg. Mech., ASCE, 118(3), 540-556.

Bažant, Z. P., Xiang, Y., and Prat, P. C. (1996). "Microplane model for concrete. I: Stress-strain boundaries and finite strain." J. Engrg. Mech., ASCE, 122(3), 245-254.

Bresler, B., and Pister, K. S. (1958). "Strength of concrete under combined stresses." J. Am. Concrete Inst., 551(9), 321-345.

Goode, C. D., and Helmy, M. A. (1967). "The strength of concrete under combined shear and direct stress." Mag. Concrete Res., 19(59), 105112.
Green, S. J., and Swanson, S. R. (1973). "Static constitutive relations for concrete." Rep. No. AFWL-TR-72-2, Air Force Weapons Lab., Kirtland Air Force Base, Albuquerque, N.M.

Hognestad, E., Hanson, N. W., and McHenry, D. (1955). “Concrete stress distribution in ultimated strength design." J. Am. Concrete Inst., 52(4), 455-477.

Kupfer, H., Hilsdorf, H. K., and Rüsch, H. (1969). “Behavior of concrete under biaxial stresses." J. Am. Concrete Inst., 66, 656-666.

Launay, P., and Gachon, H. (1971). "Strain and ultimate strength of concrete under triaxial stress." Proc., 1st Int. Conf. on Struct. Mech. in Reactor Technol. (SM: RT1), T. Jaeger, ed., European Communities, Brussels, Belgium.

Ortiz, M. (1987). "An analytical study of the localized failure modes in concrete." Mech. of Mat., 6, 159-174.

Ožbolt, J., and Bažant, Z. P. (1994). "Numerical smeared fracture analysis: nonlocal microcrack interaction approach." Rep., Dept. Civ. Engrg., Northwestern Univ., Evanston, Ill.; also Int. J. of Numer. Meth. in Engrg. (in press).

Petersson, P. E. (1981). " Crack growth and development of fracture zones in plain concrete and similar materials." Rep. No. TVBM 1006, Lund Inst. of Technol., Lund, Sweden.

Pijaudier-Cabot, G., and Bažant, Z. P. (1987). "Nonlocal damage theory." J. Engrg. Mech., ASCE, 113(10), 1512-1533.

Sinha, B. P., Gerstle, K. H., and Tulin, L. G. (1964). "Stress-strain relations for concrete under cyclic loading." J. Am. Concrete Inst., 62(2), 195-210.

van Mier, J. G. M. (1984). "Strain-softening of concrete under multiaxial loading conditions," PhD dissertation, De Technische Hogeschool Eindhoven, The Netherlands.

van Mier, J. G. M. (1986). "Multiaxial strain-softening of concrete. Part I: fracture. Part II: load histories." Mat. and Struct., Paris, France, 111(19), 179-200 